\title{
A personal journey from the joint to the heart
}

\author{
Bruce N Cronstein* \\ See related research by Palomino-Morales et al., http://arthritis-research.com/content/12/2/R71
}

\begin{abstract}
Predicting complications of diseases such as rheumatoid arthritis (RA) as well as the efficacy and toxicity of drugs used to treat the disease based on an understanding of genetic differences is leading to the development of highly individualized, personal medicine. The prevention of cardiovascular complications of RA has assumed greater importance as our ability to treat the underlying joint disease has improved and it may be possible to predict which patients with RA are at greatest risk of developing cardiovascular disease.
\end{abstract}

With the availability of increased information about the role of common genetic polymorphisms in disease susceptibility, response to therapy and toxicity of therapies, the prospect of increasingly personalized medicine is becoming a reality. Palomino-Morales and colleagues [1] report the novel observation that a common polymorphism in the gene for methylene tetrahydrofolate reductase (MTHFR) that markedly reduces enzyme activity (by as much as $65 \%$ in homozygotes) may predispose to the development of atherosclerotic cardiovascular disease (ASCVD) in patients with rheumatoid arthritis (RA).

Although RA primarily affects the joints, it is a systemic disease that clearly contributes to a marked increase in the risk for development of ASCVD (for example, [2]). The increased risk of developing ASCVD has been attributed to generalized inflammation that enhances development of atherosclerosis, the use of steroids, changes in lipid profiles and other unknown mechanisms.

Elevated homocysteine levels have long been associated with ASCVD (for example, [3]) and homocysteine is a direct toxin for the vascular endothelium. Low dose methotrexate therapy, by inhibiting MTHFR, diminishes recycling of homocysteine to methionine, leading to

*Correspondence: bruce.cronstein@nyumc.org

NYU School of Medicine, 550 First Ave, NBV16N1, New York, NY 10016, USA increases in plasma homocysteine, although folic acid supplementation abrogates the increase in homocysteine levels in methotrexate-treated patients with RA [4]. One potential contributor to homocysteine elevation is genetic alterations in MTHFR; two common polymorphisms in this enzyme have previously been reported to alter MTHFR activity (C677T and A1298C).

The A1298C polymorphism is quite common and is present in as many normal individuals ( $40 \%$ were AC heterozygotes and $10 \%$ were homozygous $\mathrm{CC}$ ) as RA patients ( $41 \%$ were heterozygotes and $10 \%$ were homozygous for the $\mathrm{C}$ allele). The striking finding by PalominoMorales and colleagues was that RA patients with cardiovascular events were more likely to have the $\mathrm{C}$ allele of A1298C than those without (62\% versus 50\%, respectively) and the accumulated risk increased over time was strongly associated with the $\mathrm{C}$ allele of the A1298C polymorphism. It is interesting to note that the polymorphism associated with more marked declines in MTHFR activity, the C677T polymorphism, was not associated with a greater risk for cardiovascular disease. The numbers were probably too small to determine whether there was an interaction between these two common polymorphisms that further contributed to risk.

In some of the patients with RA the authors were able to directly probe the health of the endothelium by measuring the flow-dependent forearm vasodilatation and found that the RA patients with the minority A1298C allele in MTHFR had diminished vasodilatory responses, consistent with a less healthy vascular endothelium.

Patients with the C677T polymorphism, but not the A1298C polymorphism, are at greater risk for developing complications of methotrexate therapy and methotrexate therapy may ameliorate the risk of ASCVD in patients with RA $[5,6]$. Thus, it would be interesting to determine whether methotrexate therapy affected the frequency of cardiovascular events in this population and whether there was any interaction between methotrexate and genetic risk for cardiovascular disease in this population. Moreover, it would be important to know how many of these patients were taking folic acid supplements since folic acid supplementation has previously been shown to lower homocysteine levels in patients taking methotrexate $[4,7-9]$, presumably by providing higher levels of 
substrate for the enzyme, and it is possible that folic acid supplementation in this group might have had a greater effect in the patients with the polymorphism on reducing risk of cardiovascular events.

More often than not, candidate genetic association studies, such as that described here, are not reproducible [10] and it is possible that this study may share the fate common to so many of these types of candidate gene studies. Nonetheless, Palmino-Morales and colleagues have made an interesting observation that may suggest a contributing factor to the development of cardiovascular disease in patients with RA. Moreover, this study provides an even greater rationale for the addition of folic acid to the therapy for RA, prevention of cardiovascular disease.

\section{Abbreviations}

ASCVD = atherosclerotic cardiovascular disease; MTHFR = methylene tetrahydrofolate reductase; $\mathrm{RA}=$ rheumatoid arthritis.

\section{Competing interests}

BNC holds or has filed applications for patents on the use of adenosine $A_{2 A}$ receptor agonists to promote wound healing and use of $A_{2 A}$ receptor antagonists to inhibit fibrosis; use of adenosine $A_{1}$ receptor antagonists to treat osteoporosis and other diseases of bone; the use of adenosine $A_{1}$ and $A_{2}$ receptor antagonists to treat fatty liver; and the use of adenosine $A_{2 A}$ receptor agonists to prevent prosthesis loosening. Consultant (within the past 2 years) King Pharmaceutical (licensee of patents on wound healing and fibrosis above). CanFite Biopharmaceuticals, Savient Pharmaceuticals, Bristol-Myers Squibb, Roche Pharmaceuticals, Cellzome, Tap (Takeda) Pharmaceuticals, Prometheus Laboratories, Regeneron (Westat, DSMB), Sepracor, Amgen, Endocyte, Protalex, Allos, Inc., Combinatorx, Kyowa Hakka. Honoraria/Speakers' Bureaus: Tap (Takeda) Pharmaceuticals. Stock: CanFite Biopharmaceuticals received for membership in Scientific Advisory Board.

\section{Acknowledgements}

This work was supported by grants from the National Institutes of Health (AR54897, AR56672, 1UL1RR029893), OSI Pharmaceuticals and the Vilcek Foundation.
Published: 13 August 2010

\section{References}

1. Palomino-Morales R, Gonzalez-Juanatey C, Vazquez-Rodriguez TR, Rodriguez L, Miranda-Filloy JA, Fernandez-Gutierrez B, Llorca J, Martin J, Gonzalez-Gay MA: A1298C polymorphism in the MTHFR gene predisposes to cardiovascular risk in rheumatoid arthritis. Arthritis Res Ther 2010, 12:R71.

2. Wolfe F, Mitchell DM, Sibley JT, Fries JF, Bloch DA, Williams CA, Spitz PW, Haga M, Kleinheksel SM, Cathey MA: The mortality of rheumatoid arthritis. Arthritis Rheum 1994, 37:481-494.

3. Smulders YM, Blom HJ: The homocysteine controversy. J Inherit Metab Dis 2010 [Epub ahead of print].

4. Morgan SL, Baggott JE, Lee JY, Alarcon GS: Folic acid supplementation prevents deficient blood folate levels and hyperhomocysteinemia during longterm, low dose methotrexate therapy for rheumatoid arthritis: implications for cardiovascular disease prevention. J Rheumatol 1998, 25:441-446.

5. Fisher MC, Cronstein BN: Metaanalysis of methylenetetrahydrofolate reductase (MTHFR) polymorphisms affecting methotrexate toxicity. J Rheumatol 2009, 36:539-545.

6. Choi HK, Hernan MA, Seeger JD, Robins JM, Wolfe F: Methotrexate and mortality in patients with rheumatoid arthritis: a prospective study. Lancet 2002, 359:1173-1177.

7. Morgan SL, Baggott JE, Koopman WJ, Krumdieck CL, Alarcon GS: Folate supplementation and methotrexate. Ann Rheum Dis 1993, 52:315-316.

8. Morgan SL, Baggott JE, Refsum H, Ueland PM: Homocysteine levels in patients with rheumatoid arthritis treated with low-dose methotrexate. Clin Pharmacol Ther 1991, 50:547-556.

9. Morgan SL, Baggott JE, Vaughn WH, Austin JS, Veitch TA, Lee JY, Koopman WJ, Krumdieck CL, Alarcón GS: Supplementation with folic acid during methotrexate therapy for rheumatoid arthritis. A double-blind, placebocontrolled trial. Ann Intern Med 1994, 121:833-841.

10. Hirschhorn JN, Lohmueller K, Byrne E, Hirschhorn K: A comprehensive review of genetic association studies. Genet Med 2002, 4:45-61.

doi:10.1186/ar3099

Cite this article as: Cronstein BN: A personal journey from the joint to the heart. Arthritis Research \& Therapy 2010, 12:134. 